Article

\title{
Application of Artificial Neural Networks, Support Vector, Adaptive Neuro-Fuzzy Inference Systems for the Moisture Ratio of Parboiled Hulls
}

\author{
Vali Rasooli Sharabiani ${ }^{1}$ (D), Mohammad Kaveh ${ }^{2}$ (D), Ebrahim Taghinezhad ${ }^{3, *(D)}$, Rouzbeh Abbaszadeh ${ }^{4}$, \\ Esmail Khalife $^{5}$ (D), Mariusz Szymanek ${ }^{6, *(D)}$ and Agata Dziwulska-Hunek ${ }^{7}$ (D)
}

check for updates

Citation: Sharabiani, V.R.; Kaveh, M.; Taghinezhad, E.; Abbaszadeh, R.; Khalife, E.; Szymanek, M.;

Dziwulska-Hunek, A. Application of Artificial Neural Networks, Support Vector, Adaptive Neuro-Fuzzy Inference Systems for the Moisture Ratio of Parboiled Hulls. Appl. Sci. 2022, 12, 1771. https://doi.org/ 10.3390/app12041771

Academic Editors: Gang Ma, Masaya Kato and

Pongphen Jitareerat

Received: 24 December 2021

Accepted: 6 February 2022

Published: 9 February 2022

Publisher's Note: MDPI stays neutral with regard to jurisdictional claims in published maps and institutional affiliations.

Copyright: (c) 2022 by the authors Licensee MDPI, Basel, Switzerland. This article is an open access article distributed under the terms and conditions of the Creative Commons Attribution (CC BY) license (https:// creativecommons.org/licenses/by/ $4.0 /)$.
1 Department of Biosystem Engineering, Faculty of Agriculture and Natural Resources, University of Mohaghegh Ardabili, Ardabil 5619911367, Iran; vrasooli@uma.ac.ir

2 Department of Petroleum Engineering, Collage of Engineering, Knowledge University, Erbil 44001, Iraq; sirwan.kaweh@knu.edu.iq

3 Department of Agricultural Technology Engineering, Moghan College of Agriculture and Natural Resources, University of Mohaghegh Ardabil, Ardabil 5619911367, Iran

4 Iranian Research Organization for Science and Technology, Agriculture Institute, Tehran 3313193685, Iran; abbaszadeh@irost.org

5 Department of Civil Engineering, Cihan University-Erbil, Kurdistan Region, Erbil 44001, Iraq; esmail.khalife@su.edu.krd

6 Department of Agricultural, Forest and Transport Machinery, University of Life Sciences in Lublin, 20-950 Lublin, Poland

7 Department of Biophysics, University of Life Sciences in Lublin, 20-950 Lublin, Poland; agata.dziwulska-hunek@up.lublin.pl

* Correspondence: e.taghinezhad@uma.ac.ir (E.T.); mariusz.szymanek@up.lublin.pl (M.S.)

\begin{abstract}
Drying as an effective method for preservation of crop products is affected by various conditions and to obtain optimum drying conditions it is needed to be evaluated using modeling techniques. In this study, an adaptive neuro-fuzzy inference system (ANFIS), artificial neural network (ANN), and support vector regression (SVR) was used for modeling the infrared-hot air (IR-HA) drying kinetics of parboiled hull. The ANFIS, ANN, and SVR were fed with 3 inputs of drying time $(0-80 \mathrm{~min})$, drying temperature $\left(40,50\right.$, and $\left.60^{\circ} \mathrm{C}\right)$, and two levels of IR power $\left(0.32\right.$ and $\left.0.49 \mathrm{~W} / \mathrm{cm}^{2}\right)$ for the prediction of moisture ratio $(M R)$. After applying different models, several performance prediction indices, i.e., correlation coefficient $\left(R^{2}\right)$, mean square error index $(M S E)$, and mean absolute error $(M A E)$ were examined to select the best prediction and evaluation model. The results disclosed that higher inlet air temperature and IR power reduced the drying time. MSE values for the ANN, ANFIS tests, and SVR training were $0.0059,0.0036$, and 0.0004 , respectively. These results indicate the high-performance capacity of machine learning methods and artificial intelligence to predict the $M R$ in the drying process. According to the results obtained from the comparison of the three models, the SVR method showed better performance than the ANN and ANFIS methods due to its higher $R^{2}$ and lower MSE.
\end{abstract}

Keywords: drying; parboiled hulls; artificial neural networks; neuro-fuzzy inference; support vector regression

\section{Introduction}

Rice is one of the oldest and most important grains on earth. Due to the increase in population and the limitations of increasing the area under rice cultivation, the most important goal in the industry is the processing of this strategic plant and the production of the highest quality crop [1]. Rice is a very valuable food and plays an important role in human nutrition. In 2020, according to the World Food and Agriculture Organization, the total world rice production was 513 million tons [2]. The nutritional value of rice has led to the use of this substance as a staple food in most countries and has a significant role in the 
nutrition of people around the world. Due to the importance of rice in the diet of Iranians after wheat, it is among the strategic goods and is the second most-consumed food by most people [3].

Parboiling is a hydrothermal process that is applied to the hulls before the conversion operation and consists of three stages: immersion, steaming, and drying. To solve the problem of rice fracture, parboiling is a useful, practical, and safe method that has a significant impact on rice self-sufficiency [4].

Drying is one of the oldest and most common processes of preserving food and agricultural products, which has greatly affected the quality of the product in terms of color, texture, size, and taste [5]. For example, it reduces the activity of water in the product and in turn reduces the microbiological activity of the product and also minimizes physical and chemical changes during storage. In drying, in addition to preventing food spoilage due to the invasion of microorganisms or chemical reactions, the weight of the food is reduced due to the loss of moisture in the product, and savings in transportation, packaging, and storage costs [6].

In the past, solar energy was used to dry a variety of agricultural products and food, but due to inappropriate changes in food quality, lack of enough control during the drying process, long drying time, and unsanitary, the product has many problems in using this method, so it is necessary to use new technology in the drying process [7].

Hot-air drying is the most common method for drying food and agricultural products. In this method, the whole product is completely and uniformly exposed to drying. Low energy efficiency, long drying time, and low quality of products are among the disadvantages of this method [8]. On the other hand, the use of IR radiation for drying agricultural products is increasing due to its many advantages (faster heat transfer, uniform heating of the product, and high value of dried food). IR radiations are shone on the product [9]. Depending on the type of product and the wavelength of the radiated radiation, part of the radiation passes through the product, a percentage of it is reflected, and finally, a part is absorbed and penetrates the product and will be converted into thermal energy. The product then heats up sharply and the thermal gradient inside the body increases sharply over a short period of time. Because air transmits IR radiation energy, IR energy heats the product without heating the ambient air [10]. Drying of food and agricultural products using combined infrared and hot-air drying can be a good substitute for single hot and infrared drying. The interaction of the two drying leads to an efficient drying process. When materials are exposed to IR radiation, the radiation penetrates into the product and, as a result, increases the molecular vibration, thus facilitating heat dissipation and reducing the drying time [11,12]. Rapid heating of the material increases the speed of moisture movement to the surface. The flow of hot and dry air removes moisture from the surface, thus increasing mass transfer. Other advantages of infrared and hot-air drying are high drying speed, high energy efficiency, better product quality, and efficient use of space [13]. Many products have been dried using IR-HA drying, including shiitake mushroom [14], mint leaves [15], white mulberry [13], Kiwi and Turnip [16,17], sweet potato [12], and savory leaves [18].

Drying is a very complex and uncertain phenomenon and there are unknown factors for them. This phenomenon has been modeled with different levels of complexity [19]. Predicting the drying kinetics of agricultural products under different conditions is very important and basic for equipment and process design, quality control, energy and fuel management, and selection of appropriate storage [20]. In order to model food processing processes such as drying and predicting the desired parameters in the design and development of systems, various methods and equations have been used. In situations where the relationships between independent and dependent parameters are complex, mathematical modeling methods will face limitations such as selecting parameters, the application of assumptions to solve equations, and the complexity of solving equations. Therefore, the best choice is to use intelligent optimization methods [21]. These methods include artificial neural networks (ANNs), adaptive fuzzy-neural inference system (ANFIS), 
and support vector regression (SVR), which allow adequate and accurate prediction of the drying process in industrial applications.

Many authors have successfully used ANN, ANFIS, and SVR to describe the drying properties of many agricultural and food products. Kaveh et al. [22] conducted a study to predict the moisture ratio $(M R)$, energy, and exergy of onions during drying with a semi-industrial type of continuous dryer by using two different approaches ANNs and ANFIS. The results showed that the ANFIS model provided better results for all predicted parameters. In another study, the $M R$, energy, and exergy analysis of drying of blackberry in an IR-HA dryer with ultrasonic pretreatment were predicted by ANNs and ANFIS [23]. Ziaforoughi et al. [24] performed comparisons between mathematical and inference models to predict the $M R$ of quince in the IR drying. According to the results, the ANFIS model with $\left(R^{2}=0.998\right)$ had better performance than the mathematical models. SVR has also been used to predict the moisture content $(M C)$ of wood during the drying process [25]. Several studies have employed ANNs to estimate the $M R$ of different products in different dryers, including green peas [26], apricot [27], stevia [28], basil seed [29], and yam slices [30]. Therefore, in this study, ANN, ANFIS, and SVR are evaluated to predict the moisture drying ratio of rice in an IR-HA dryer under different operating conditions (two levels of infrared power and three levels of inlet air temperature).

Previous studies have generally focused on neural networks and semi-empirical models. These methods are powerful tools for modeling complex phenomena such as the drying process, but these methods provide district information based on drying behavior, and therefore it is inevitable to consider different models for precise simulation of the drying process. The number of studies comparing ANN, ANFIS, and SVR methods based on drying characteristics is limited in the literature. Therefore, the purposes of the present study are (a) investigation of the effect of drying temperature $\left(40,50\right.$, and $\left.60^{\circ} \mathrm{C}\right)$ at two levels of IR power $\left(0.32\right.$ and $\left.0.49 \mathrm{~W} / \mathrm{cm}^{2}\right)$ on parboiled hulls moisture ratio (b) the evaluation of the different topologies of ANN models as shaped by the selection of the networks, activation functions, training algorithm, the neuron and the hidden layer number, (c) the evaluation of different first-order Takagi-Sugeno type ANFIS models with different number and types of membership function for each input and output, training algorithm, number of output membership functions and number of fuzzy rules for predicting the drying characteristics of parboiled hulls, (d) the comparison of the various learning algorithms of the support vector regression method for estimating the $M R$ of drying of parboiled hulls.

\section{Materials and Methods}

\subsection{Description of Dataset}

\subsubsection{Sample Preparation}

To conduct the research, the Fajr rice cultivar was prepared from the research farm of the Iranian Rice Research Institute in Amol. The samples were separately saved in plastic bags at $5 \pm 1{ }^{\circ} \mathrm{C}$ refrigerators. For the experiment, the broken seeds were separated from the healthy seeds to reduce the test error. The experiments were performed in the laboratory of the Department of Biosystem Engineering of the University of Mohaghegh Ardabili, Iran. In this state, the $M C$ value of samples was $11 \pm 1 \%$, wet basis (w.b.). To find the $M C, 10 \mathrm{~g}$ of the hull was heated in an oven (Memert model D06836, Germany) at a temperature of $130{ }^{\circ} \mathrm{C}$ for $24 \mathrm{~h}$. Fajr rice cultivar has a weight of one thousand seeds of $21.6 \mathrm{~g}$. The average length, thickness, and width of rice samples were 10.60, 2.11, and $1.98 \mathrm{~mm}$, respectively.

The $M C$ of paddy samples was obtained from the following equation [22]:

$$
M C=\frac{m_{1}-m_{2}}{m_{1}}
$$

where $M C$ (moisture content) is based on a wet basis; $\mathrm{m}_{1}$ is the initial sample weight $(\mathrm{kg})$, $\mathrm{m}_{2}$ is the final sample weight after drying $(\mathrm{kg})$. 


\subsubsection{Parboiling Hulls}

A device made by Taghinezhad et al. [31] was used for the immersion of hulls. This device includes a tank and a temperature control system. During immersion, a water temperature control system was used to maintain the water temperature. A mesh chamber (sampler) was used to float the hull in the tank. The samples were placed in a sampler and the water temperature in the tank was constant throughout the soaking period with an accuracy of $\pm 0.5^{\circ} \mathrm{C}$. Therefore, for soaking, $200 \mathrm{~g}$ of paddy samples were added to $1000 \mathrm{~mL}$ of deionized water, for a water to rice ratio of 5:1 [32]. The samples were soaked in a water bath and the temperature was set at $65^{\circ} \mathrm{C} \pm 0.5^{\circ} \mathrm{C}$ for $180 \mathrm{~min}$ to achieve the best quality of parboiled rice [33]. The experiment was performed in three replications. Approximately $200 \mathrm{~g}$ of the sample was used in each experiment.

\subsection{Pre-Processing \\ Drying Oven}

After immersing the hull, the samples were taken out of the distilled water, and then the extra water was absorbed from the sample surface using a towel. The samples were then transferred to a combined IR-HA drying with three levels of hot air temperature $\left(40,50\right.$, and $\left.60^{\circ} \mathrm{C}\right)$ and airspeed of $1 \mathrm{~m} / \mathrm{s}$. It is worth mentioning that this dryer has a temperature control system (with an accuracy of $\pm 0.01^{\circ} \mathrm{C}$ ) and two $500 \mathrm{~W}$ IR lamps (Philips model, Flemish, Belgium) which were installed in the upper part of the dryer chamber with a height of $30 \mathrm{~cm}$. A centrifugal fan with an inverter (Vincker VSD2, ABB Co., Taipei, Taiwan) was used to create the inlet air velocities. During the experiments, the ambient temperature was between 20 and $26^{\circ} \mathrm{C}$ and the relative moisture was between $22 \%$ and $27 \%$. The samples were weighed using a digital scale with $0.001 \mathrm{~g}$ resolution (AND GF-600, Japan). The IR-HA dryer was turned on $30 \mathrm{~min}$ before the start of each experiment to ensure stable and uniform conditions at the beginning of drying. The drying process was performed at three temperature levels $\left(40,50\right.$, and $\left.60^{\circ} \mathrm{C}\right)$, two levels of IR power $(0.32$ and $0.49 \mathrm{~W} / \mathrm{cm}^{2}$ ) by a combined IR-HA drying. Samples with a weight of $200 \mathrm{~g}$ were put on a $10 \mathrm{~cm}$ by $10 \mathrm{~cm}$ surface in the IR-HA chamber. Also, the bed depth of the sample was $5 \mathrm{~mm}$. The samples were dried by a dryer until the $M C$ reached $11 \%$ on a dry basis.

Moisture ratio was calculated by Equation (2) [7]:

$$
M R=\frac{M_{t}-M_{e}}{M_{b}-M_{e}}
$$

where $M R$ is the moisture ratio, $M_{t}, M_{b}$, and $M_{e}$ are moisture content at time $t$, initial, and equilibrium moisture content $(\% \mathrm{db})$, respectively.

\subsection{Model Development}

\subsubsection{Artificial Neural Network}

The neural network consists of a connected group of artificial neurons that processes information using a computational connection approach [34]. ANN is an adaptive system whose structure is based on the information given to it through the network during the learning phase. ANN is able to learn the relationship between input and output data by having enough information [35].

The experimental phase occurs at the same time as the learning phase, in which the network tests itself with another piece of data (Figure 1). 


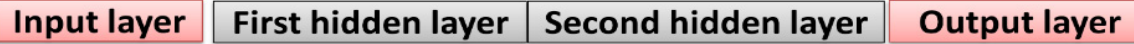

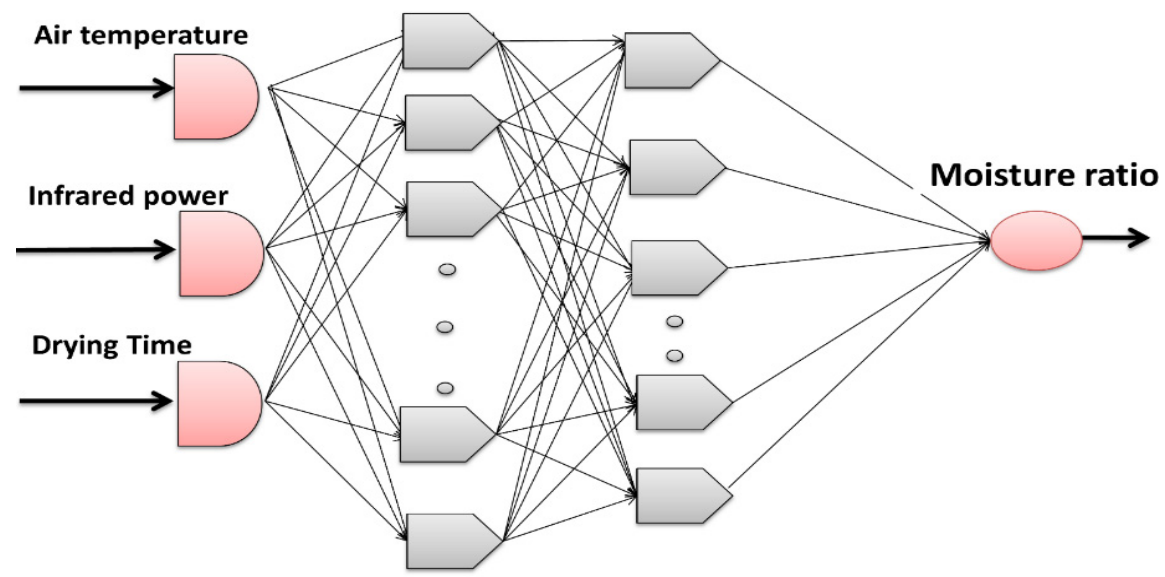

Figure 1. Selected ANN structure with two hidden layers.

In this structure, by changing the type of network (Feed Forward Back Propagation (FFBP)), Cascade Forward Back Propagation (CFBP), training algorithm (LevenbergMarquardt (LM) and Bayesian Regulation (BR)), the amount of data used for learning, testing and evaluating the best network structure to achieve the optimal network were investigated.

Levenberg-Marquardt's algorithm is a way to find the minimum of a multivariate nonlinear function that has been employed as a standard method for solving the leastsquares problem for nonlinear functions [36,37].

Bayesian Regulation: this method does not require accurate information and the complete history of a fact. In fact, it can use incomplete and inaccurate information to achieve very acceptable results in estimating the current or future state of a system $[37,38]$.

FFBP: The static (etc. time-dependent) structure of this network is used in engineering and scientific computing. Neurons, which are elements of the signal processor, are connected by synaptic connections between the feed-forward layers. Input-output connections may be performed by nonlinear mapping functions (activation functions). Error back-propagation algorithm is the main method for updating FFBP network weights to perform calculations. The first layer is the data entry layer. No processing is done in this layer. The last layer is the network output layer, and the user or control system can receive the processed information [39]. In this network, the neurons of each layer are connected to the neurons of the prior layer's neurons. The inputs of this network pass through layers to reach the output layer (Figure 2).

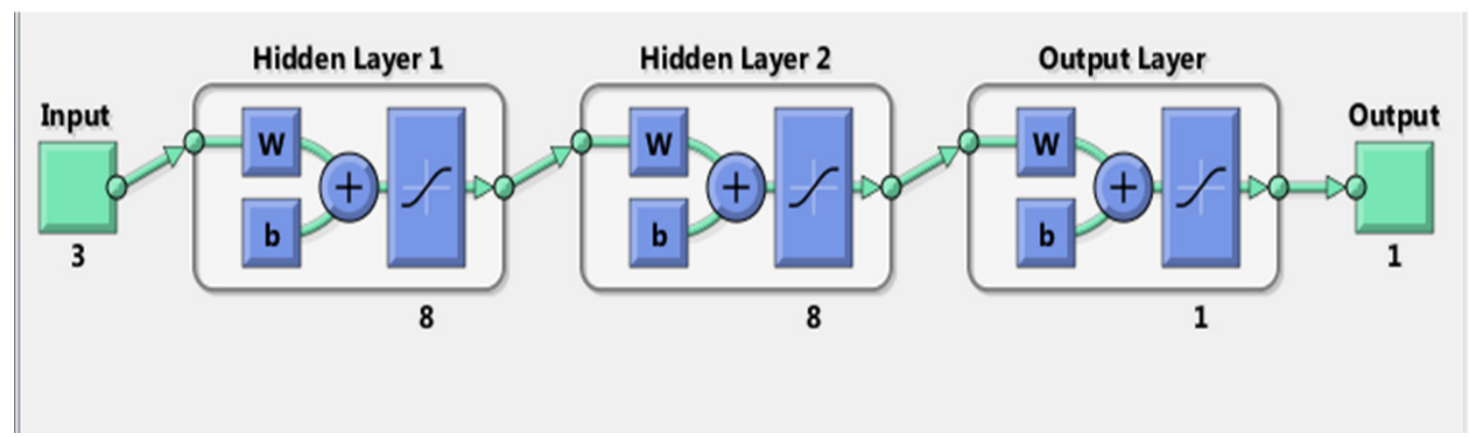

Figure 2. Feed Forward Back Propagation structure with two hidden layers.

CFBP: These networks, like the feedback network, use an error back-propagation algorithm to update the weights. But the main feature of this network is that the neurons in each layer are connected to all the previous layer neurons (Figure 3) [40]. The activation functions and algorithms used for the CFBP network are similar to those for the FFBP 
network. It is noteworthy that due to the increase in interneuron connections, the network used becomes more complex because its computational volume increases [37].

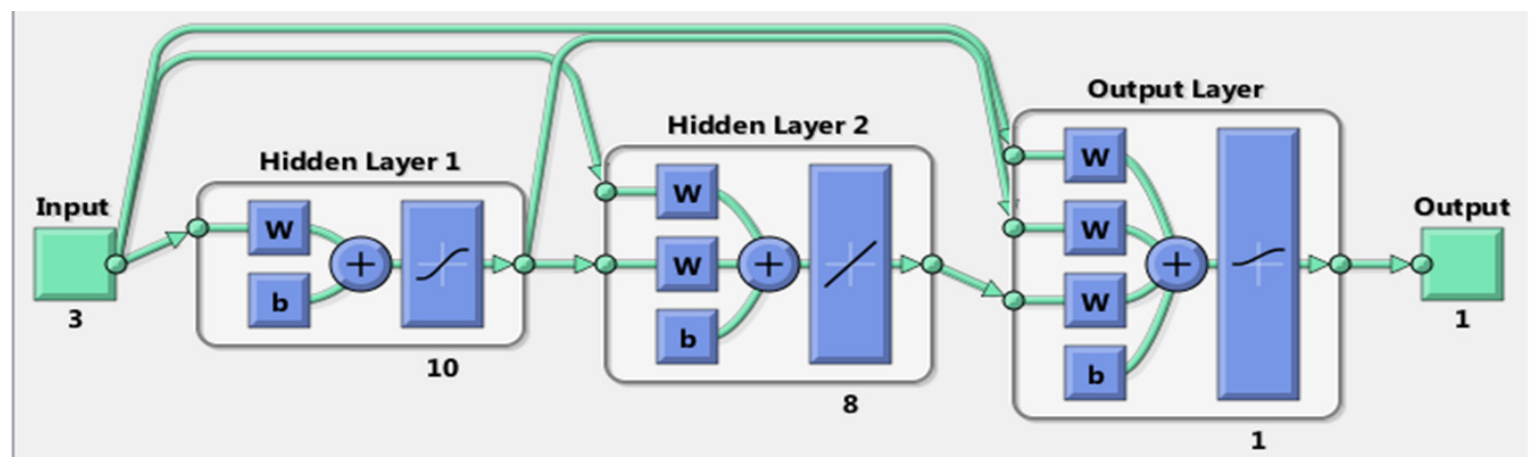

Figure 3. Cascade Forward Back Propagation structure with two hidden layers.

Determining the number of neurons and layers is the main important issue for designing ANN algorithms [41]. The number of neurons has a direct impact on ANN algorithm learning. For instance, if fewer neurons are considered then the time of the network is reduced while the network has not learned enough, and the network has not faced all the possible cases. Selecting a high number of neurons then the calculation takes more time and extra memory capacity is required however it results in excellent learning [42]. Overall, trial and error are used to determine the number of neurons and layers [43]. The perceptron multilayer neural network is an FFBP or CFBP with three inputs (infrared power, air temperature, and drying time), one or two hidden layers, and one output layer. However, there was no general rule for choosing the number of neurons in the hidden layer. Both the input and output were considered to have one neuron, and the stepwise searching method was used to determine the optimal number of hidden neurons in the range of 3-15 (trial and error) [41]. Also, ANN will finish the procedure of the network after reaching a minimum error and maximum $R^{2}$ value

During the training process, ANNs, with the help of training data, learn the connections between neurons in each training epoch to bring these predicted values closer to the desired outcomes and maximize the efficiency of the prediction model. During the network training process, composite variables such as the number of hidden layers, neurons, and training epochs were assessed by trial and error. $X_{j}$ is weighted inputs for each neuron in jth layer and computed as below [44]:

$$
X_{j}=\sum_{i=1}^{N} W_{i j} \times Y_{i}+b_{j}
$$

where $\mathrm{N}$ is the number of output layer neurons, $\mathrm{W}_{\mathrm{ij}}$ is the weight coefficient between the $i$ th and jth layers, $Y_{i}$ is the ith neuron output, $b_{j}$ is the bias of $j$ th neuron for FFBP and CFBP networks

During the training process, these weights and the constant values that are added to them, called biases, change continuously until the error is minimized. After obtaining each $X_{j}$, an activation function is used for modifying it. To optimize the network structure, three activation functions of the hyperbolic tangent sigmoid (Tansig (TAN)), logarithmic sigmoid transfer function (Logsig (LOG)), and linear function (Purlin (PUR)) were used (Figure 4) [28]. 


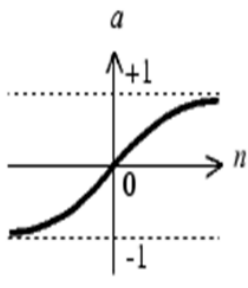

$a=\operatorname{tansig}(n)$
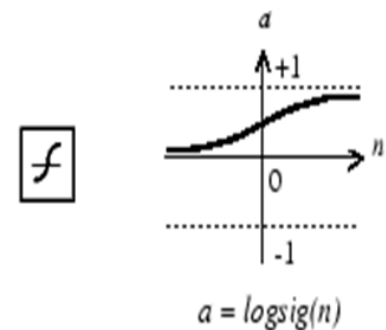

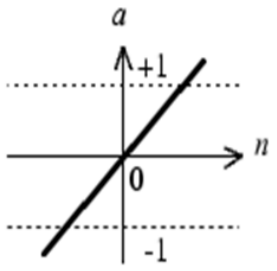

$a=\operatorname{Durelin}(n)$

Figure 4. Activation functions of Tansig, Logsig, and Purlin.

Three transfer functions were employed to achieve the optimized network structure $[45,46]$.

$$
\begin{gathered}
Y_{j}=\frac{2}{\left(1+\exp \left(2 X_{j}\right)\right)-1} \text { Tansig } \\
Y_{j}=\frac{1}{1+\exp \left(-X_{j}\right)} \text { Logsig } \\
Y_{j}=X_{j} \text { Purlin }
\end{gathered}
$$

\subsubsection{ANFIS}

The ANFIS model is a soft computation model that serves as a combination of neural networks and fuzzy systems [20]. Hence, it provides a synergetic effect that incorporates the advantages of both systems in linear and non-linear processes. ANFIS constitutes an integration of fuzzy inference systems (FIS) and ANNs, maintaining both advantageous features in a single structure, such as the trainability, the optimizable connectionist structure, the human expert knowledge in linguistic terms using if-then rules. In ANFIS, the main problem is determining the type of membership function and their degree of membership, for which there is no specific solution, and by using trial and error, the best structure of the model is determined. For this purpose, in training the structure of ANFIS, the hybrid method was used, which is a combination of the least-squares method and the back propagation method. ANFIS can be potently employed to find the optimum relationship between a set of input and output data effectively. Fuzzy rules can be generated from the given input-output data by implementing the Takagi-Sugeno fuzzy inference system, thus this system is always interpretable in terms of fuzzy if-then rules in contrast with ANNs where the knowledge gained by training is split in every network weight and is not possible to be interpreted by humans [20]. The inputs and outputs parameters are related together using some fuzzy rules known as IF-THEN rules. In the present study, fuzzy IF-THEN rules were used to evaluate the $M R$ of parboiled hulls. ANFIS is a five-layered model that utilizes fuzzy logic controllers in solving problems at a high rate with a minimum steady-state error. The ANFIS model consists of five layers whose functions are fuzzification, multiplication, normalization, defuzzification, and summation, respectively [42,47]. The designed ANFIS system consists of three inputs (inlet air temperature $(\mathrm{T})$, infrared power $(\mathrm{P})$, and drying time (DT)), and from the other side one outlet (MR (f)) (Figure 5). Fuzzy if-then rules are written for this structure based on Equations (7) and (8). 


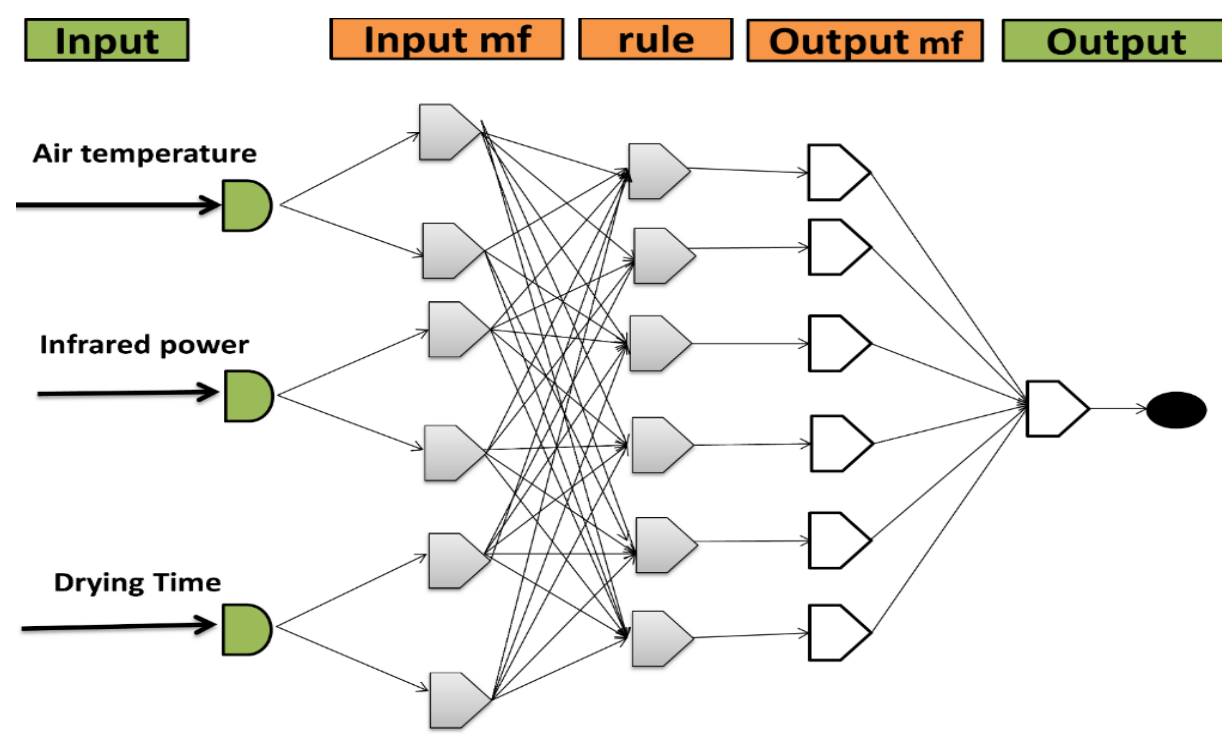

Figure 5. An ANFIS model based on Sugeno-type fuzzy rule.

In this study, fuzzy if-then rules consisted of four rules, three of them for inputs ( $T, P$, and DT) and one rule for output (f), as in the following forms [30].

$$
\begin{aligned}
& \text { Rule } 1: \text { if } T \text { is } A_{1}, P \text { is } B_{1} \text { and } D T \text { is } C_{1} \\
& \text { then } f_{1}=p_{1} T+q_{1} P+r_{1} D T+s_{1} \\
& \text { Rule } 1: \text { if } T \text { is } A_{2}, P \text { is } B_{2} \text { and } D T \text { is } C_{2} \\
& \text { then } f_{2}=p_{2} T+q_{2} P+r_{2} D T+s_{2}
\end{aligned}
$$

where $\mathrm{T}$ is the input air temperature $\left({ }^{\circ} \mathrm{C}\right), \mathrm{P}$ is the infrared power $\left(\mathrm{W} / \mathrm{cm}^{2}\right), \mathrm{DT}$ is the drying time (min), $\mathrm{f}$ is the $M R, \mathrm{~A}_{1}, \mathrm{~A}_{2}, \mathrm{~B}_{1}, \mathrm{~B}_{2}, \mathrm{C}_{1}$ and $\mathrm{C}_{2}$ are the language indicators, $\mathrm{r}_{1}, \mathrm{r}_{2}$, $\mathrm{q}_{1}, \mathrm{q}_{2}, \mathrm{p}_{1}, \mathrm{p}_{2}, \mathrm{~s}_{1}$, and $\mathrm{s}_{2}$ are the linear coefficients of the output function and $\mathrm{f}_{1}$ and $\mathrm{f}_{2}$ are first-degree polynomials.

The first layer (fuzzification): each node in the first layer is an adaptive node and the corresponding node function is written as follows [39]:

$$
\begin{aligned}
O^{1}{ }_{A i} & =\mu_{A i}(T) & i & =1,2 \\
O^{1}{ }_{B j} & =\mu_{B j}(P) & i & =1,2 \\
O^{1}{ }_{A i} & =\mu_{C i}(D T) & i & =1,2
\end{aligned}
$$

where, $\mu_{\mathrm{Ai}}, \mu_{\mathrm{Bj}}$, and $\mu_{\mathrm{Cj}}$ are the membership functions from the language variables of $\mathrm{A}, \mathrm{B}$, and $\mathrm{C}$.

In the second layer; known as multiplication; each rule functions as a node in the ANFIS network using soft-min or product to determine the binding factor of the rule. The input signal in Equation (12) is multiplied by this layer and exits the product.

$$
O^{2}{ }_{i}=w_{i}=\mu_{A i}(T) \times \mu_{B i}(P) \times \mu_{C i}(D T), \ldots . i=1,2
$$

In the third layer (normalization): the ratio ith of the laws of weight governing the total force of each rule can be found by Equation (13) [22]:

$$
\mathrm{O}^{3}{ }_{i}=\bar{w}=\frac{w_{i}}{w_{1}+w_{2}}
$$

where $\mathrm{w}$ is the normalization rate. 
The fourth layer (defuzzification): each $w_{i}$ value is related to the result of linear regression $f_{i}$ in this layer and finally the output result is generated in Equation (14) [30]:

$$
O^{4}{ }_{i}=w_{i} f_{i}=w_{i}\left(p_{i} T+q_{i} P+r_{i} D T+s_{i}\right)
$$

Fifth layer (dummation): the total output is obtained using follow Equation (15) [25]:

$$
O^{5}{ }_{i}=\sum_{i} w_{i} f_{i}=\frac{\sum_{i} w_{i} f_{i}}{\sum_{i} w_{i}} i=1,2
$$

In this paper, two models of ANN and ANFIS with 163 datasets were used to predict the $M R$ of parboiled hulls. In order to model the network, the data were randomly divided into two groups, of which $75 \%$ (114 data) were used for training and $25 \%$ (49 data) were used for testing the models. The data were then trained using MATLAB software (ver4.01) and with one or two hidden layers.

\subsubsection{Support Vector Regression (SVR)}

The support vector machine (SVM)/support vector regression (SVR) has been lately utilized in multi-various fields for the prediction of quality characteristics. While support vector machines (SVMs) are a well-known method for classification, SVR is a lesser known, but effective, method for solving regression problems and estimating function with a supervised learning approach. Unlike SVM, where the output is a separate set, in this method, by estimating a multivariate function, the output is obtained with a continuous value [48]. Support vector machine is considered a non-parametric technique because it is based on nuclear functions. SVR estimates a continuous-valued function that encodes the fundamental interrelation between a given input and its corresponding output in the training data. This function then can be used to predict outputs for given inputs that were not included in the training set [49]. This algorithm has been used in cases such as face recognition, text classification, and bioinformatics. Learning algorithms include the following types: linear, quadratic, cubic, and gaussian [50]. One of the main advantages of using SVR is that it has very few adjustable parameters which in turn provides less effort and diminishes the need for experimentation for the purpose of finding appropriate architecture [51]. In this study, all data were used to train SVR algorithms. The architecture of the SVR model is presented in Figure 6.

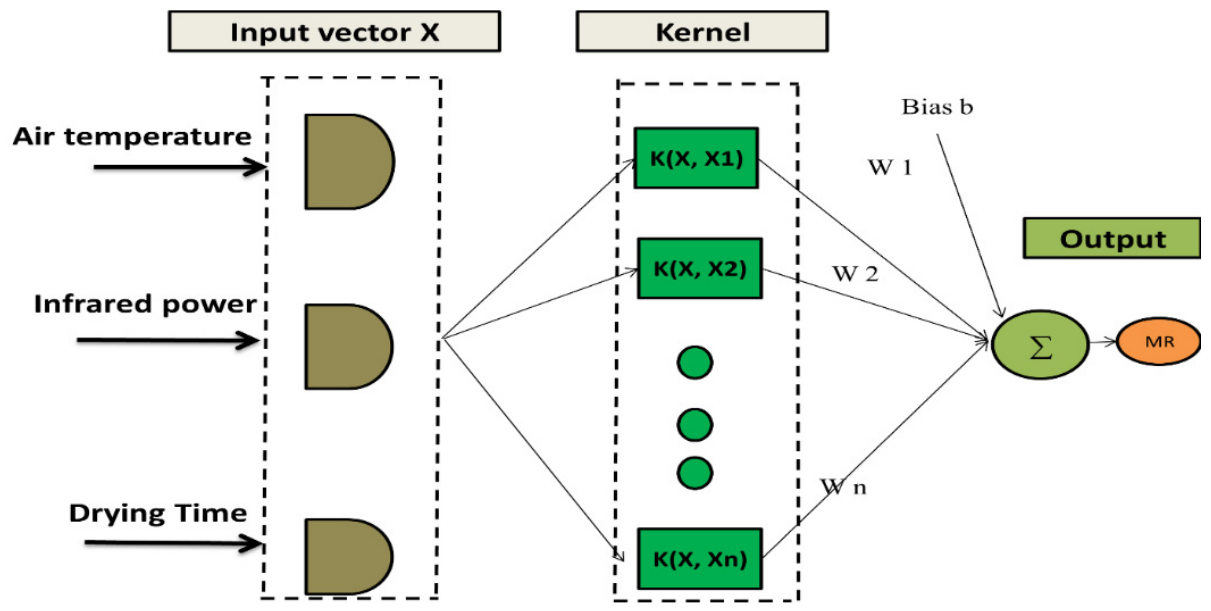

Figure 6. Architecture of the SVR used for modeling the wheat moisture content in this study.

\subsection{Model Evaluation Methods}

The input layer in all three networks to predict the features studied in this study included inlet air temperature, infrared power, drying time and the output layer also included MR (Table 1). 
Table 1. Input parameters for ANN and ANFIS to predict the $M R$ of parboiled hulls.

\begin{tabular}{cccccc}
\hline Parameter & Sign & Unit & Category & Min & Max \\
\hline Inlet air temperature & $T$ & ${ }^{\circ} \mathrm{C}$ & Input & 40 & 60 \\
Infrared power & $P$ & $\mathrm{~W} / \mathrm{cm}^{2}$ & Input & 0.32 & 0.49 \\
Drying time & $D T$ & $\mathrm{~min}$ & Input & 0 & 68 \\
Moisture ratio & $M R$ & - & Output & 0.2 & 1 \\
\hline
\end{tabular}

Table 1 presents the inputs and output factors. Therefore, three neurons including inlet air temperature, IR power, and drying time were employed in the input layer of ANN and ANFIS networks and one neuron was allocated for the output layer $(M R)$. The Neural Network Toolbox of MATLAB software (v4.01) was also employed to design and evaluate ANN, ANFIS, and SVR to predict the MR of parboiled hulls.

It is recommended to normalize the data along a correct spectrum to stop any numerical overflow during the training of ANN, ANFIS, and SVR. Taghinezhad et al. [23] noted that normalization can help improve the network. Input and output values are standardized between 0.00 and 1.00 using Equation (16). [23].

$$
X_{n}=\frac{X_{b}-X_{\min }}{X_{\max }-X_{\min }}
$$

where $X_{n}$ is the normalized value of the parameter, $X_{b}$ is the real value of each parameter, $X_{\max }$ is the maximum value of the desired parameter and $X_{\min }$ is the minimum value of the desired parameter.

Three indicators (R-square, mean squared error (MSE), and mean absolute error (MAE)) were applied for the evaluation of the ANN, ANFIS, and SVR. These indices are shown in Equations (17)-(19), respectively [52].

$$
\begin{gathered}
R^{2}=\frac{\left[\sum_{i=1}^{N}\left(X_{i}-X_{\text {mean }}\right)^{2}\right]-\left[\sum_{i=1}^{N}\left(X_{i}-X_{p}\right)\right]}{\left[\sum_{i=1}^{N}\left(X_{i}-X_{\text {mean }}\right)^{2}\right]} \\
M S E=\frac{\sum_{i=1}^{N}\left(X_{i}-X_{p}\right)^{2}}{N} \\
M A E=\frac{1}{N} \sum_{i=1}^{N}\left|X_{i}-X_{p}\right|
\end{gathered}
$$

where $X_{i}$ and $X_{p}$ are the measured (actual) and predicted values of output, $X_{\text {mean }}$ is the average predicted values and $\mathrm{N}$ is total data

\section{Results and Discussion}

\subsection{Drying Kinetics}

Figure 7 shows a diagram of the $M R$ and drying time ( $\mathrm{min}$ ). The results showed that with increasing IR power, the rate of moisture removal from the hulls was faster and the drying time was reduced. Based on this, the minimum and maximum drying time were obtained in IR power of 0.49 and $0.32 \mathrm{~W} / \mathrm{cm}^{2}$, respectively. IR waves reduced the drying time and increased the drying rate due to the direct penetration of energy on the grain surface and its absorption as heat [27]. In other words, high IR power caused more mass and heat transfer and more severe moisture reduction [53]. In addition, the drying time of the products was decreased at higher inlet temperatures, so the longest and shortest process times were related to drying at 40 and $60^{\circ} \mathrm{C}$, respectively. Increasing the temperature of the product surface led to an increase in mobility of water molecules and as a result easier migration of these molecules from the internal parts to the product surface [54]. Increasing 
the temperature on the one hand increased the moisture absorption capacity of the air due to increasing the temperature difference between the air and the product and on the other hand caused faster heating of the product and better evaporation of water from it and ultimately reduced drying time [55]. Chayjan et al., [40] in a study of drying the thin layer of sour cherry using IR-HA showed that by changing the infrared power from 500 to $1500 \mathrm{~W}$, increasing the air temperature from 35 to $65^{\circ} \mathrm{C}$, the drying time in the length of the drying process was reduced. Similar findings were observed in the drying of mint leaves [15] and pumpkin [55] and potato [41].
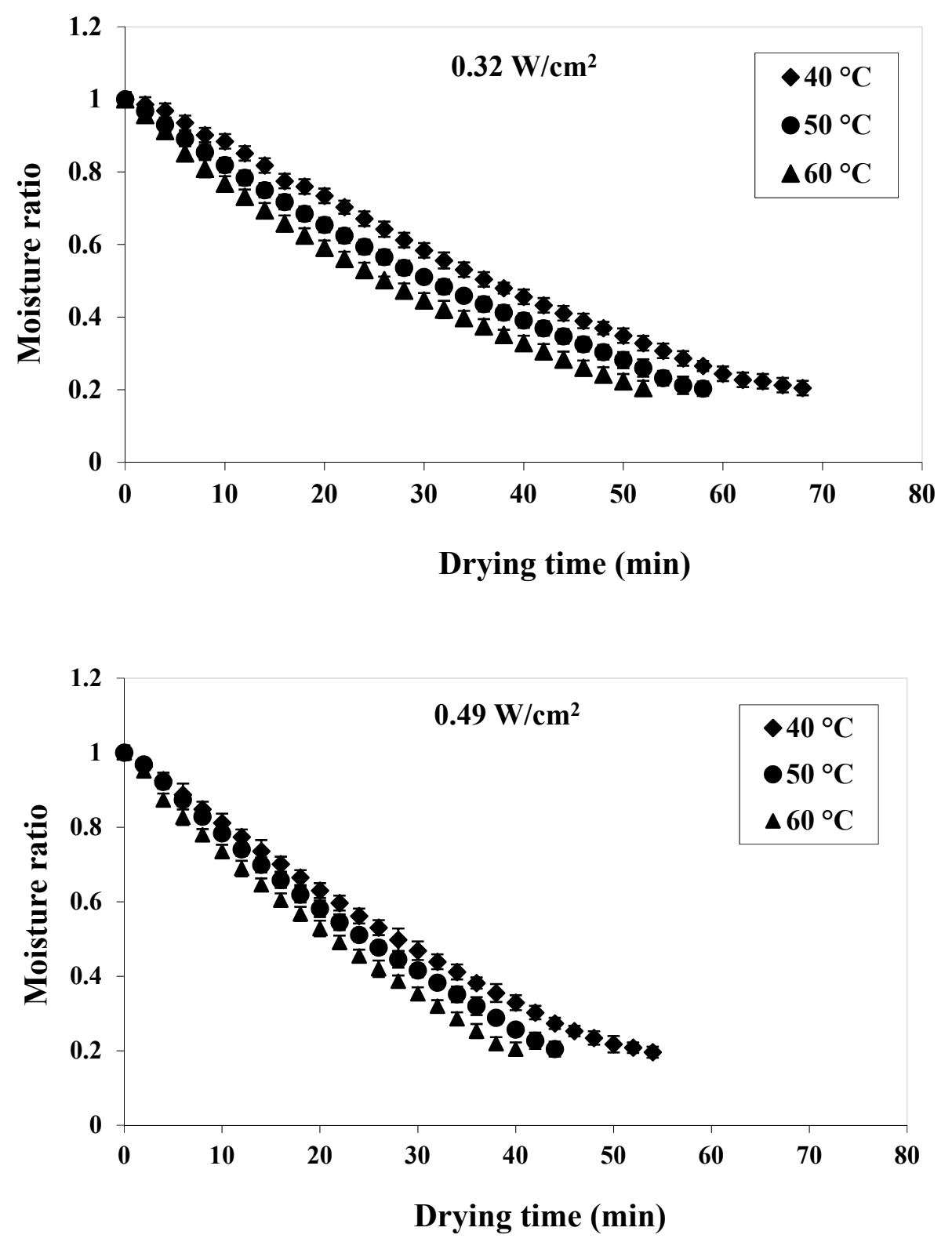

Figure 7. Effect of air temperature on $M R$ in different IR powers during parboiled hulls drying.

\subsection{Artificial Neural Networks}

Due to the influence of the number of neurons, the type of functions, and learning algorithms on the output of the models, different networks were designed and evaluated. Table 2 shows the comparison of different structures in determining the $M R$ of parboiled hulls. 
Table 2. Best selected topologies, including testing and training, different layers and neurons for FFBP, and CFBP for moisture ratio.

\begin{tabular}{|c|c|c|c|c|c|c|c|c|c|}
\hline \multirow{2}{*}{ Network } & \multirow{2}{*}{$\begin{array}{c}\text { Training } \\
\text { Algorithm }\end{array}$} & \multirow{2}{*}{$\begin{array}{l}\text { Activation } \\
\text { Functions }\end{array}$} & \multirow{2}{*}{$\begin{array}{l}\text { Number of Layers } \\
\text { and Neurons }\end{array}$} & \multirow{2}{*}{$M S E$} & \multicolumn{2}{|c|}{ Test } & \multicolumn{2}{|c|}{ Train } & \multirow{2}{*}{ Epoch } \\
\hline & & & & & $R^{2}$ & $M A E$ & $R^{2}$ & $M A E$ & \\
\hline FFBP & LM & TAN-TAN-TAN & $3-8-8-1$ & 0.0059 & 0.9991 & 0.0423 & 0.9967 & 0.0618 & 144 \\
\hline FFBP & BR & PUR-TAN-TAN & $3-5-5-1$ & 0.0073 & 0.9982 & 0.0501 & 0.9711 & 0.0924 & 118 \\
\hline CFBP & LM & TAN-LOG-PUR & $3-10-8-1$ & 0.0068 & 0.9989 & 0.0449 & 0.9968 & 0.0599 & 68 \\
\hline CFBP & $\mathrm{BR}$ & TAN-TAN-TAN & $3-5-5-1$ & 0.0080 & 0.9979 & 0.0533 & 0.9899 & 0.0855 & 132 \\
\hline
\end{tabular}

Table 2 displays the best selected ANN models with their topology, activation functions, and various algorithms used to anticipate the $M R$ of parboiled hulls in an IR-HA drying. Among all the topologies depicted in Table 2, the powerful one for estimating the $M R$ of parboiled hulls with topology 3-8-8-1 and activation function TANSIG-TANSIGTANSIG belong to the LM algorithm. The error values of MSE, MAE, and $R^{2}$ of the network were $0.0059,0.4234$, and 0.9991 , respectively.

In a study, Sadeghi et al. [56] reported that a model contained an input layer with four neurons (radiation intensity, slice thickness, distance between slices and infrared lamps), two hidden layers ( 5 and 7 neurons) and one neuron in the output layer (MR) with TANSIG transfer function and the LM training algorithm was the best model for predicting kiwi slice in an infrared dryer. Beigi and Torki [57] predicted the moisture ratio of the onion slice in the microwave drying with the highest $R^{2}=0.997$ and the lowest MSE $=0.000228$ values (Best structure: three inputs including microwave power, samples thickness and drying time, the multi-layer feed-forward network with a topology of 3-18-1, LevenbergMarquardt training algorithm and transfer function of LOG- PUR). Various studies have been performed on the drying $M R$ of other crops such as potato [41], apricot [27], and stevia [28] using ANN.

\subsection{ANFIS}

The results of the best ANFIS structure for estimating the $M R$ of parboiled hulls in different conditions are given in Table 3 .

Table 3. Information on the best model for the MR of parboiled hulls in ANFIS.

\begin{tabular}{cc}
\hline Result & ANFIS Modeling Results \\
\hline Sugeno-type & Fuzzy structure \\
Genfis1 & Basic FIS for training \\
$3-3-3$ & Number of membership functions for each entry \\
Gaussian (gaussmf) & Type of membership function for each entry \\
1000 & Epoch \\
Linear & Type of membership function for each output \\
Hybrid & Training algorithm \\
3 & Number of entries \\
27 & Number of output membership functions \\
114 & Number of data for training \\
49 & Number of data to evaluate \\
27 & Number of fuzzy rules \\
\hline
\end{tabular}

In the present study, the findings of an experimental investigation and the modeling prediction using ANFIS were compared and employed to estimate the MR of parboiled hulls. Information on the most preside algorithms is shown in Table 3.

In ANFIS analysis, as in other models used, the best architecture must be designed. To achieve this goal, different ANFIS models have been designed using a trial-and-error method to determine the number of fuzzy rules in output prediction. This model used eight types of membership functions: psigmf, dsigmf, pimf, Gasuss2mf, Gaussmf, gbellmf, 
trimf, and trapmf. As can be seen, the Gaussian membership function (gaussmf) is widely employed in ANFIS modeling using training and test data as a membership function. It was found that this membership function due to the lower values of MSE and higher $R^{2}$ and 27 fuzzy rules with structure $(3 \times 3 \times 3)$ showed the best performance and estimation compared to all membership functions to predict the $M R$ of parboiled hulls in infrared-hot air drying (Table 3). The number of functional membership rules was three to five. This membership function is the most applied in ANFIS networks. Indeed, it is actually suitable in terms of values and relation to the types of membership functions. Finally, the three fuzzy rules for each input exceed the number of other membership rules. Thus, 27 fuzzy rules $(3 \times 3 \times 3)$ revealed the highest efficiency for predicting the $M R$ of parboiled hulls in an IR-HA drying (Table 3). The findings obtained for ANFIS modeling are tabulated in Table 4. It should be noted that the accuracy of the ANFIS model could be improved by increasing the number of membership functions; however, it drastically increases the number of rules. As observed, the lowest MSE and the highest $R^{2}$ were provided by the ANFIS algorithm. In fact, the model potentially predicted the $M R$ with a coefficient of determination of 0.995 and the MSE of 0.0036 . In a study conducted by Ziaforoughi et al. [24] who used a similar technique to estimate the $M R$ of quince using IR drying, they claimed the values of 0.9999 and 0.0041 for $R^{2}$ and $R M S E$, respectively. In another research, Kaveh et al. [26] used the ANFIS model to predict the green peas moisture ratio $(M R)$ by using a hot air-rotary drum dryer. They obtained $R^{2}=0.9996$ and $M S E=0.0026$ for the prediction of the moisture ratio. Other researchers, including Taghinezhad et al. [17], Okonkwo et al. [21], and Ojediran et al. [30] also used the ANFIS model in the drying process, and the optimal performance of the ANFIS model for the modeling has been shown in these studies.

Table 4. The results of different ANFIS arrangements for estimating $M R$ obtained from testing and training data.

\begin{tabular}{ccccccc}
\hline \multirow{2}{*}{$\begin{array}{c}\text { Type of Membership } \\
\text { Function for Each Entry }\end{array}$} & $\begin{array}{c}\text { Number of Membership } \\
\text { Functions for Each Entry }\end{array}$ & MSE & \multicolumn{3}{c}{ Test } & \multicolumn{3}{c}{ Train } \\
\cline { 3 - 7 } & $3-3-3$ & 0.0036 & 0.9995 & 0.038 & 0.9991 & 0.042 \\
gaussmf & $3-3-3$ & 0.0050 & 0.9992 & 0.0414 & 0.9972 & 0.0468 \\
trimf & $3-5-3$ & 0.0064 & 0.9989 & 0.0451 & 0.9978 & 0.0459 \\
trapmf & & $\boldsymbol{R}^{\mathbf{2}}$ & $\boldsymbol{M A E}$ & $\boldsymbol{R}^{\mathbf{2}}$ \\
\hline
\end{tabular}

\subsection{Support Vector Regression}

Different types of SVR algorithms were investigated, the results of which are presented in Table 5. Corresponding MSE and $R^{2}$ values were 0.0182 and 0.9997 for the prediction of moisture ratio. A comparison between the predicted and experimental moisture ratios for data sets for the SVR is shown in Figure 8.

Table 5. Results of various learning algorithms of the support vector regression method for estimating the $M R$ obtained.

\begin{tabular}{cccc}
\hline Type of Algorithm & $\mathbf{M S E}$ & $\boldsymbol{R}^{\mathbf{2}}$ & $\mathbf{M A E}$ \\
\hline Linear & 0.0023 & 0.9611 & 0.0352 \\
Quadratic & 0.0004 & 0.9997 & 0.0182 \\
Cubic & 0.0005 & 0.9990 & 0.0201 \\
Fine Gaussian & 0.0018 & 0.9705 & 0.0335 \\
Medium Gaussian & 0.0006 & 0.9985 & 0.0203 \\
Coarse Gaussian & 0.0010 & 0.9814 & 0.0235 \\
\hline
\end{tabular}




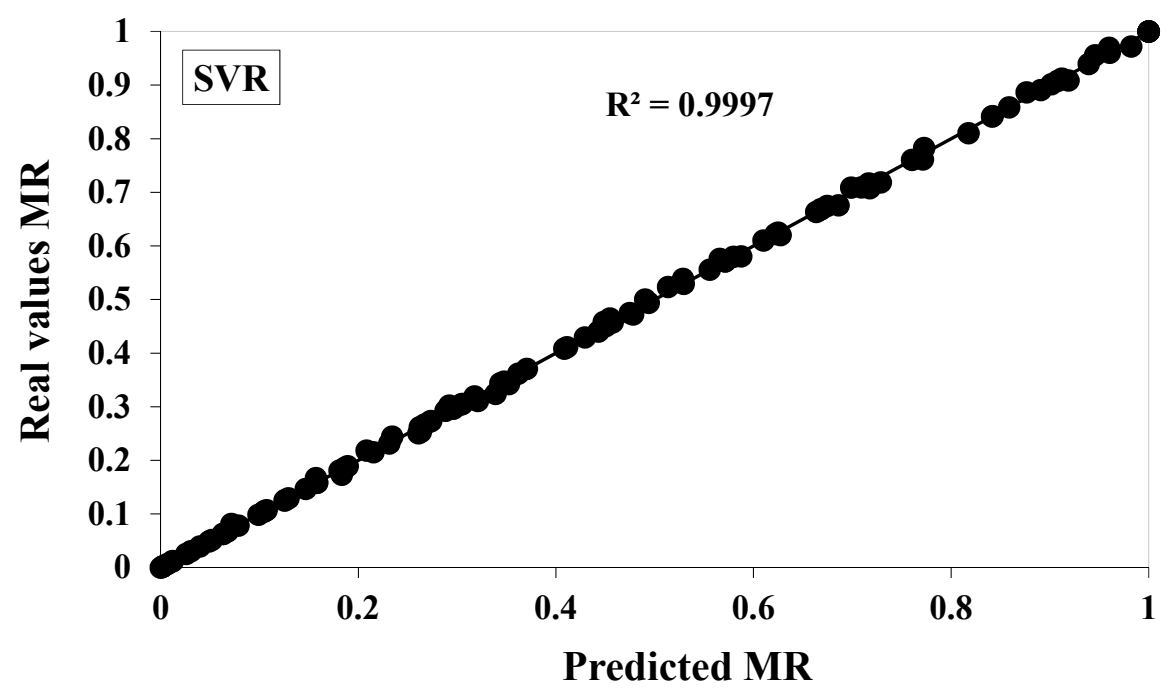

Figure 8. Predicted $M R$ data vs. real values, and for quadratic algorithm the SVR method.

According to the results, it seems that quadratic, cubic, and Gaussian algorithms have higher average power in estimating $M R$, respectively.

In a study conducted by Abdollahpour et al. [58], they reported that the ANN model has a greater ability than the SVR model to predict the moisture content of wheat at harvest time. In another study, Taheri et al. [59] modeled the moisture content for drying the lentil seeds in a microwave fluidized bed dryer using the SVR and ANN. They showed that the ANN model performed better with $R^{2}=0.999$ than the SVR with $R^{2}=0.995$.

\subsection{Comparison of ANN, ANFIS, and SVR}

The present study attempted to investigate the potentials of ANN, ANFIS, and SVR modeling techniques to estimate the $M R$ of parboiled hulls. In order to have a measurement of the efficiency of the developed equations, three statistical functions were used (i.e., MSE, $M A E$, and $R^{2}$ ). Table 6 shows the values of ANN, ANFIS, and SVR models. Accordingly, the ANFIS model provided higher accuracy than ANN. Furthermore, the predicted results against the actual values for the Gaussian membership function and the ANN are presented in Figure 9. Kaveh et al. [22] and Taghinezhad et al. [23] in a comparative application of ANN and ANFIS to predict the MR of onion and blackberry, respectively, reported that the ANFIS model performs better in predicting the MR. Amini et al. [29] and Satorabi et al. [27] also used ANN- genetic algorithm and ANFIS- to predict the MR of basil seed and apricot crops. They showed that the ANFIS model performed better due to the higher $R^{2}$ value. Similarly, Zadhossein et al., [60] reported that the ANFIS model was slightly better than multilayer feed-forward neural networks models for the prediction of $M R$, energy, and exergy of Cantaloupe Slice in a microwave dryer. Bakhshipour et al. [28] reported that the ANN model was more accurate than the ANFIS and mathematical model for the prediction of stevia leaves in an infrared-assisted continuous hybrid solar dryer. However, Abbaspour-Giandeh et al. [61] and Chasiotis et al. [20] for drying quince and Echium amoenum Fisch. \& C. A. Mey., respectively, were shown that compared to ANN and mathematical models, ANFIS is reported as the most suitable model for $M R$ prediction

Table 6. Comparison of prediction behavior of parboiled hulls drying in an IR-HA drying using ANN, ANFIS, and SVR.

\begin{tabular}{cccc}
\hline & & MR & \\
\cline { 2 - 4 } & ANN & ANFIS & SVR \\
\hline$M S E$ & 0.0059 & 0.0036 & 0.0004 \\
$M A E$ & 0.0423 & 0.0388 & 0.0182 \\
$R^{2}$ & 0.9991 & 0.9995 & 0.9997 \\
\hline
\end{tabular}



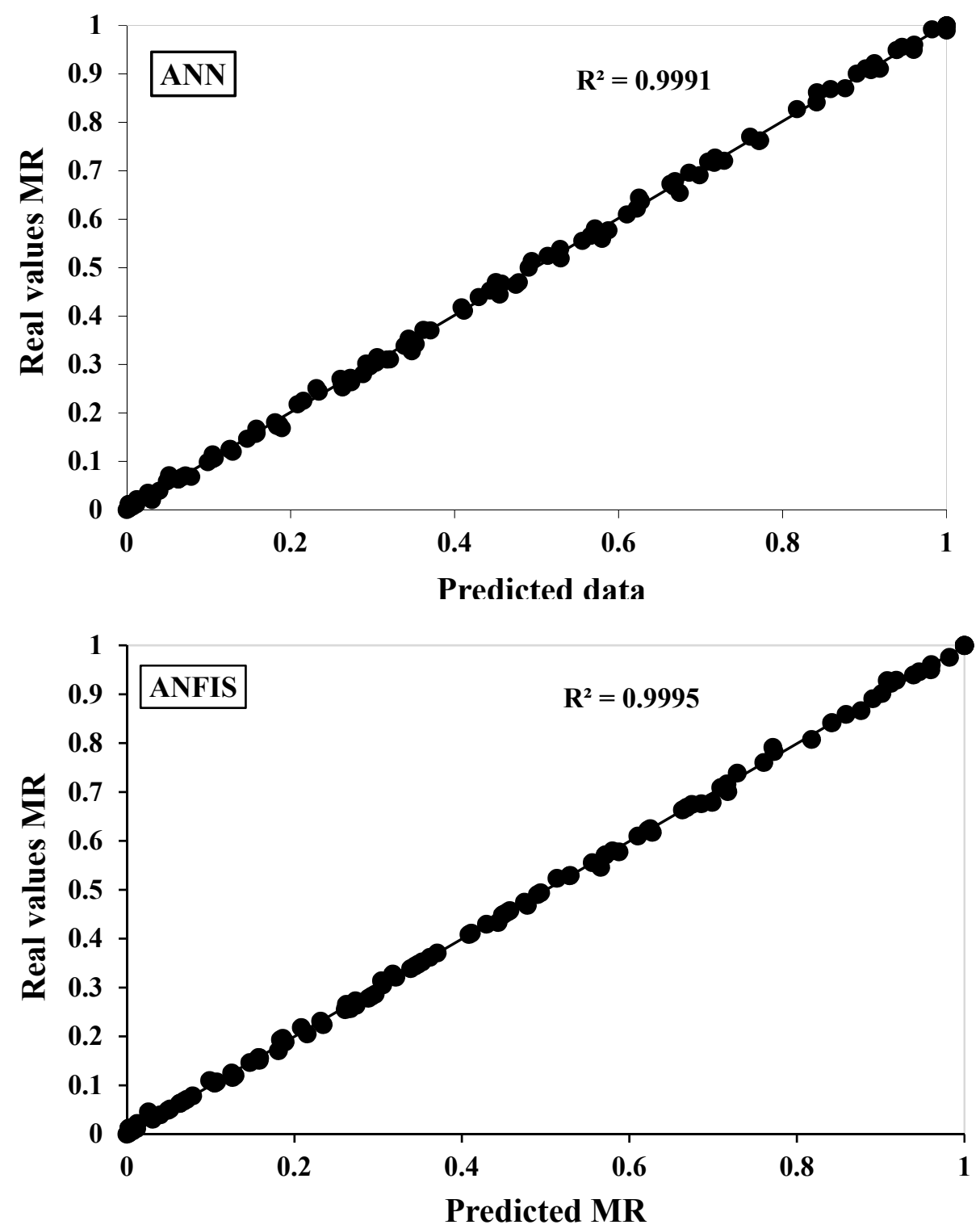

Figure 9. Predicted $M R$ data vs. real values, for the Gaussian membership function (gaussmf) and the ANN.

Although the training and evaluation of the SVR method were different from the other two models and the calibration results were reported with all the data in Table 6, the mean square error was significantly lower than the ANN and ANFIS results.

\section{Conclusions}

Drying is a useful crop preservation method, increases the shelf-life of the crops, and decreases storage, packaging, and transportation costs. There are several methods for drying and each one of them has a specific procedure. Analyzing and finding the optimum procedure condition could be obtained using modeling and simulation techniques. The data set was obtained at three temperature levels $\left(40,50\right.$, and $\left.60^{\circ} \mathrm{C}\right)$, two levels of IR power $\left(0.32\right.$ and $\left.0.49 \mathrm{~W} / \mathrm{cm}^{2}\right)$ in an IR-HA drying. Drying time was reduced at higher temperature values of the inlet air between $40{ }^{\circ} \mathrm{C}$ and $60{ }^{\circ} \mathrm{C}$. Based on the data set, three nonlinear prediction models (ANN, ANFIS, and SVR) were designed to estimate the parboiled hulls $M R$. All three models were designed with one output variable $(M R)$ and three inlet variables (inlet air temperature, IR power, and drying time). To select the best model for accurately predicting the $M R$, the developed models were compared with each other. To select the best model, the coefficient of determination obtained and the total ranking for 
each model was calculated and examined. According to the experimental data set, the performance prediction of the ANFIS model $\left(R^{2}=0.9995\right)$ was higher than the ANN model $\left(R^{2}=0.9991\right)$. Therefore, the ANFIS model provided higher performance in predicting the $M R$ of parboiled hulls in comparison with ANNs with higher $R^{2}$, lower MSE, and MAE. The SVR method also showed considerable capability in training the model for predicting the $M R$ of parboiled hulls compared to the other two methods.

Author Contributions: Conceptualization, V.R.S. and M.K.; methodology, E.T. and R.A.; software, R.A.; validation, M.K. and E.T.; formal analysis, V.R.S. and R.A.; resources, M.K.; data curation, M.K., M.S. and A.D.-H.; writing—original draft preparation, V.R.S. and M.K.; writing—review and editing, M.S., M.K. and E.K.; visualization, E.K. All authors have read and agreed to the published version of the manuscript.

Funding: This research received no external funding.

Institutional Review Board Statement: Not applicable.

Informed Consent Statement: Not applicable.

Data Availability Statement: Data sharing is not applicable to this article.

Conflicts of Interest: The authors declare that they have no known competing financial interest or personal relationship that could have appeared to influence the work reported in this paper.

\section{References}

1. Shen, L.; Gao, M.; Zhu, Y.; Liu, C.; Wang, L.; Kamruzzaman, M.; Liu, C.; Zheng, X. Microwave drying of germinated brown rice: Correlation of drying characteristics with the final quality. Innov. Food Sci. Emerg. Technol. 2021, 70, 102673. [CrossRef]

2. Nosrati, M.; Zare, D.; Nassiri, S.M.; Chen, G.; Jafari, A. Experimental and numerical study of intermittent drying of rough rice in a combined FIR-dryer. Dry. Technol. 2021, 1-13. [CrossRef]

3. Golpour, I.; Guiné, R.P.F.; Poncet, S.; Golpour, H.; Chayjan, R.A.; Parian, J.A. Evaluating the heat and mass transfer effective coefficients during the convective drying process of paddy (Oryza sativa L.). J. Food Process Eng. 2021, 44, e13771. [CrossRef]

4. Taghinezhad, E.; Khoshtaghaza, M.H.; Minaei, S.; Latifi, A. Effect of Soaking Temperature and Steaming Time on the Quality of Parboiled Iranian Paddy Rice. Int. J. Food Eng. 2015, 11, 547-556. [CrossRef]

5. Kaveh, M.; Abbaspour-Gilandeh, Y.; Nowacka, M. Optimisation of microwave-rotary drying process and quality parameters of terebinth. Biosyst. Eng. 2021, 208, 113-130. [CrossRef]

6. Onwude, D.I.; Hashim, N.; Janius, R.; Abdan, K.; Chen, G.; Oladejo, A.O. Non-thermal hybrid drying of fruits and vegetables: A review of current technologies. Innov. Food Sci. Emerg. Technol. 2017, 43, 223-238. [CrossRef]

7. Jeevarathinam, G.; Pandiselvam, R.; Pandiarajan, T.; Preetha, P.; Balakrishnan, M.; Thirupathi, V.; Kothakota, A. Infrared assisted hot air dryer for turmeric slices:Effect on drying rate and quality parameters. LWT 2021, 144, 111258. [CrossRef]

8. Ren, Z.; Yu, X.; Yagoub, A.E.A.; Fakayode, O.A.; Ma, H.; Sun, Y.; Zhou, C. Combinative effect of cutting orientation and drying techniques (hot air, vacuum, freeze and catalytic infrared drying) on the physicochemical properties of ginger (Zingiber officinale Roscoe). LWT 2021, 144, 111238. [CrossRef]

9. Salehi, F. Recent Applications and Potential of Infrared Dryer Systems for Drying Various Agricultural Products: A Review. Int. J. Fruit Sci. 2019, 20, 586-602. [CrossRef]

10. Huang, D.; Yang, P.; Tang, X.; Luo, L.; Sunden, B. Application of infrared radiation in the drying of food products. Trends Food Sci. Technol. 2021, 110, 765-777. [CrossRef]

11. Rekik, C.; Besombes, C.; Hajji, W.; Gliguem, H.; Bellagha, S.; Mujumdar, A.S.; Allaf, K. Study of interval infrared Airflow Drying: A case study of butternut (Cucurbita moschata). LWT 2021, 147, 111486. [CrossRef]

12. Onwude, D.I.; Hashim, N.; Abdan, K.; Janius, R.; Chen, G. The effectiveness of combined infrared and hot-air drying strategies for sweet potato. J. Food Eng. 2018, 241, 75-87. [CrossRef]

13. Golpour, I.; Kaveh, M.; Chayjan, R.A.; Guiné, R.P.F. Optimization of Infrared-convective Drying of White Mulberry Fruit Using Response Surface Methodology and Development of a Predictive Model through Artificial Neural Network. Int. J. Fruit Sci. 2020, 20, S1015-S1035. [CrossRef]

14. Zhang, J.; Yagoub, A.E.A.; Sun, Y.; Arun, M.S.; Ma, H.; Zhou, C. Role of thermal and non-thermal drying techniques on drying kinetics and the physicochemical properties of shiitake mushroom. J. Sci. Food Agric. 2021, 102, 214-222. [CrossRef] [PubMed]

15. Ye, L.; El-Mesery, H.S.; Ashfaq, M.M.; Shi, Y.; Zicheng, H.; Alshaer, W. Analysis of energy and specific energy requirements in various drying process of mint leaves. Case Stud. Therm. Eng. 2021, 26, 101113. [CrossRef]

16. Taghinezhad, E.; Kaveh, M.; Szumny, A. Thermodynamic and Quality Performance Studies for Drying Kiwi in Hybrid Hot Air-Infrared Drying with Ultrasound Pretreatment. Appl. Sci. 2021, 11, 1297. [CrossRef]

17. Taghinezhad, E.; Kaveh, M.; Szumny, A. Optimization and Prediction of the Drying and Quality of Turnip Slices by ConvectiveInfrared Dryer under Various Pretreatments by RSM and ANFIS Methods. Foods 2021, 10, 284. [CrossRef] [PubMed] 
18. Darvishi, H.; Farhudi, Z.; Behroozi-Khazaei, N. Multi-objective optimization of savory leaves drying in continuous infrared-hot air dryer by response surface methodology and desirability function. Comput. Electron. Agric. 2020, 168, 105112. [CrossRef]

19. Cheng, S.; Su, W.; Yuan, L.; Tan, M. Recent developments of drying techniques for aquatic products: With emphasis on drying process monitoring with innovative methods. Dry. Technol. 2021, 39, 1577-1594. [CrossRef]

20. Chasiotis, V.; Nadi, F.; Filios, A. Evaluation of multilayer perceptron neural networks and adaptive neuro-fuzzy inference systems for the mass transfer modeling of Echium amoenum Fisch. \& C. A. Mey. J. Sci. Food Agric. 2021, 101, 6514-6524. [CrossRef]

21. Okonkwo, C.E.; Olaniran, A.F.; Adeyi, O.; Adeyi, A.J.; Ojediran, J.O.; Adewumi, A.D.; Iranloye, Y.M.; Erinle, O.C. Drying characteristics of fermented-cooked cassava chips used in the production of complementary food: Mathematical and Gaussian process regression modeling approaches. J. Food Process Eng. 2021, 44, e13715. [CrossRef]

22. Kaveh, M.; Chayjan, R.A.; Golpour, I.; Poncet, S.; Seirafi, F.; Khezri, B. Evaluation of exergy performance and onion drying properties in a multi-stage semi-industrial continuous dryer: Artificial neural networks (ANNs) and ANFIS models. Food Bioprod. Process. 2021, 127, 58-76. [CrossRef]

23. Taghinezhad, E.; Kaveh, M.; Khalife, E.; Chen, G. Drying of organic blackberry in combined hot air-infrared dryer with ultrasound pretreatment. Dry. Technol. 2020, 39, 2075-2091. [CrossRef]

24. Ziaforoughi, A.; Yousefi, A.R.; Razavi, S.M. A Comparative Modeling Study of Quince Infrared Drying and Evaluation of Quality Parameters. Int. J. Food Eng. 2016, 12, 901-910. [CrossRef]

25. Zhang, D.-Y.; Zhu, L.-K.; Yin, W.-F.; Gui, H.-J. Notice of Retraction: A novel modeling method of wood moisture content for drying process. In Proceedings of the 2010 International Conference on Machine Learning and Cybernetics, Qingdao, China, 11-14 July 2010; Volume 4, pp. 1920-1924. [CrossRef]

26. Kaveh, M.; Abbaspour-Gilandeh, Y.; Chen, G. Drying kinetic, quality, energy and exergy performance of hot air-rotary drum drying of green peas using adaptive neuro-fuzzy inference system. Food Bioprod. Process. 2020, 124, 168-183. [CrossRef]

27. Satorabi, M.; Salehi, F.; Rasouli, M. The Influence of Xanthan and Balangu Seed Gums Coats on the Kinetics of Infrared Drying of Apricot Slices: GA-ANN and ANFIS Modeling. Int. J. Fruit Sci. 2021, 21, 468-480. [CrossRef]

28. Bakhshipour, A.; Zareiforoush, H.; Bagheri, I. Mathematical and intelligent modeling of stevia (Stevia Rebaudiana) leaves drying in an infrared-assisted continuous hybrid solar dryer. Food Sci. Nutr. 2020, 9, 532-543. [CrossRef]

29. Amini, G.; Salehi, F.; Rasouli, M. Drying kinetics of basil seed mucilage in an infrared dryer: Application of GA-ANN and ANFIS for the prediction of drying time and moisture ratio. J. Food Process. Preserv. 2021, 45, e15258. [CrossRef]

30. Ojediran, J.O.; Okonkwo, C.E.; Adeyi, A.J.; Adeyi, O.; Olaniran, A.F.; George, N.E.; Olayanju, A.T. Drying characteristics of yam slices (Dioscorea rotundata) in a convective hot air dryer: Application of ANFIS in the prediction of drying kinetics. Heliyon 2020, 6 , e03555. [CrossRef]

31. Taghinezhad, E.; Khoshtaghaza, M.H.; Suzuki, T.; Minaei, S.; Brenner, T. Quantifying the relationship between degree of starch gelatinization of rice and moisture-electrical conductivity of paddy during soaking. J. Food Process Eng. 2016, 39, 442-452. [CrossRef]

32. Marshall, W.E.; Wadsworth, J.I.; Verma, L.R.; Velupillai, L. Determining the degree of gelatinization in parboiled rice: Comparison of a subjective and an objective method. Cereal Chem. 1993, 70, 226-230.

33. Taghinezhad, E.; Khoshtaghaza, M.H.; Minaei, S.; Suzuki, T.; Brenner, T. Relationship Between Degree of Starch Gelatinization and Quality Attributes of Parboiled Rice During Steaming. Rice Sci. 2016, 23, 339-344. [CrossRef]

34. Khan, I.H.; Sablani, S.S.; Joardder, M.U.H.; Karim, M.A. Application of machine learning-based approach in food drying: Opportunities and challenges. Dry. Technol. 2020, 1-17. [CrossRef]

35. Aghbashlo, M.; Hosseinpour, S.; Mujumdar, A.S. Application of Artificial Neural Networks (ANNs) in Drying Technology: A Comprehensive Review. Dry. Technol. 2015, 33, 1397-1462. [CrossRef]

36. Kocabas, F.; Korkmaz, M.; Sorgucu, U.; Donmez, S. Modeling of heating and cooling performance of counter flow type vortex tube by using artificial neural network. Int. J. Refrig. 2010, 33, 963-972. [CrossRef]

37. Demuth, H.; Beale, M.; Hagan, M. Neural Network Toolbox 5; The MathWorks: Natick, MA, USA, 2007.

38. Amiri Chayjan, R.; Esna-Ashari, M. Comparison between artificial neural networks and mathematical models for estimating equilibrium moisture content in raisin. Agric. Eng. Int. CIGR J. 2010, 12, 158-166.

39. Chakraborty, S.; Gautam, S.P.; Sarma, M.; Hazarika, M.K. Adaptive neuro-fuzzy interface system and neural network modeling for the drying kinetics of instant controlled pressure drop treated parboiled rice. Food Sci. Technol. Int. 2021, 27, 746-763. [CrossRef]

40. Chayjan, R.A.; Kaveh, M.; Khayati, S. Modeling some drying characteristics of sour cherry (Prunus cerasus L.) under infrared radiation using mathematical models and artificial neural networks. Agric. Eng. Int. CIGR J. 2014, 16, $265-279$.

41. Wang, H.; Liu, Z.-L.; Vidyarthi, S.K.; Wang, Q.-H.; Gao, L.; Li, B.-R.; Wei, Q.; Liu, Y.-H.; Xiao, H.-W. Effects of different drying methods on drying kinetics, physicochemical properties, microstructure, and energy consumption of potato (Solanum tuberosum L.) cubes. Dry. Technol. 2020, 39, 418-431. [CrossRef]

42. Okonkwo, C.E.; Olaniran, A.F.; Adeyi, A.J.; Adeyi, O.; Ojediran, J.O.; Erinle, O.C.; Mary, I.Y.; Taiwo, A.E. Neural network and adaptive neuro-fuzzy inference system modeling of the hot air-drying process of orange-fleshed sweet potato. J. Food Process. Preserv. 2022, e16312. [CrossRef]

43. Mingyi, F.; Tongjun, L.; Jiwei, H.; Rensheng, C.; Xionghui, W.; Xuedan, S.; Wenqian, R. Artificial neural network modeling and genetic algorithm optimization for cadmium removal from aqueous solutions by reduced graphene oxide-supported nanoscale zero-valent iron (nzvi/rgo) composites. Materials 2017, 10, 544. 
44. Afkhamipour, M.; Mofarahi, M.; Borhani, T.N.G.; Zanganeh, M. Prediction of heat capacity of amine solutions using artificial neural network and thermodynamic models for $\mathrm{CO}_{2}$ capture processes. Heat Mass Transf. 2018, 54, 855-866. [CrossRef]

45. Kaveh, M.; Chayjan, R.A. Prediction of some physical and drying properties of terebinth fruit (pistacia atlantica 1.) Using artificial neural networks. Acta Sci. Pol. Technol. Aliment. 2014, 13, 65-78. [CrossRef] [PubMed]

46. Kaveh, M.; Chayjan, R. Mathematical and neural network modelling of terebinth fruit under fluidized bed drying. Res. Agric. Eng. 2016, 61, 55-65. [CrossRef]

47. Elijah, O.C.; Philomena, K.I.; Joseph, T.N.; Paschal, E.O. ANFIS, ANN and RSM modeling of moisture content reduction of cocoyam slices. J. Food Processing Preserv. 2022, 46, e16032.

48. Awad, M.; Khanna, R. Support vector regression. In Efficient Learning Machines; Apress: Berkeley, CA, USA, 2015 ; pp. 67-80.

49. Esmaeili, M.; Salimi, A.; Drebenstedt, C.; Abbaszadeh, M.; Bazzazi, A.A. Application of PCA, SVR, and ANFIS for modeling of rock fragmentation. Arab. J. Geosci. 2014, 8, 6881-6893. [CrossRef]

50. Zhang, N.; Leatham, K. Feature selection based on SVM in photo-thermal infrared (IR) imaging spectroscopy classification with limited training samples. WSEAS Trans. Signal Processing 2017, 13, 285-292.

51. Mia, M.; Dhar, N.R. Prediction and optimization by using SVR, RSM and GA in hard turning of tempered AISI 1060 steel under effective cooling condition. Neural Comput. Appl. 2019, 31, 2349-2370. [CrossRef]

52. Sharabiani, V.R.; Kaveh, M.; Abdi, R.; Szymanek, M.; Tanaś, W. Estimation of moisture ratio for apple drying by convective and microwave methods using artificial neural network modeling. Sci. Rep. 2021, 11, 1-12. [CrossRef]

53. Sadeghi, E.; Movagharnejad, K.; Asl, A.H. Parameters optimization and quality evaluation of mechanical properties of infrared radiation thin layer drying of pumpkin samples. J. Food Process Eng. 2019, 43, e13309. [CrossRef]

54. Jeevarathinam, G.; Pandiselvam, R.; Pandiarajan, T.; Preetha, P.; Krishnakumar, T.; Balakrishnan, M.; Thirupathi, V.; Ganapathy, S.; Amirtham, D. Design, development, and drying kinetics of infrared-assisted hot air dryer for turmeric slices. J. Food Process Eng. 2021, e13876. [CrossRef]

55. Sadeghi, E.; Movagharnejad, K.; Asl, A.H. Mathematical modeling of infrared radiation thin-layer drying of pumpkin samples under natural and forced convection. J. Food Process. Preserv. 2019, 43, e14229. [CrossRef]

56. Sadeghi, E.; Asl, A.H.; Movagharnejad, K. Mathematical modelling of infrared-dried kiwifruit slices under natural and forced convection. Food Sci. Nutr. 2019, 7, 3589-3606. [CrossRef] [PubMed]

57. Beigi, M.; Torki, M. Experimental and ANN modeling study on microwave dried onion slices. Heat Mass Transf. 2021, 57, 787-796. [CrossRef]

58. Abdollahpour, S.; Kosari-Moghaddam, A.; Bannayan, M. Prediction of wheat moisture content at harvest time through ANN and SVR modeling techniques. Inf. Process. Agric. 2020, 7, 500-510. [CrossRef]

59. Taheri, S.; Brodie, G.; Gupta, D. Optimised ANN and SVR models for online prediction of moisture content and temperature of lentil seeds in a microwave fluidised bed dryer. Comput. Electron. Agric. 2021, 182, 106003. [CrossRef]

60. Zadhossein, S.; Abbaspour-Gilandeh, Y.; Kaveh, M.; Szymanek, M.; Khalife, E.; Samuel, O.D.; Amiri, M.; Dziwulski, J. Exergy and Energy Analyses of Microwave Dryer for Cantaloupe Slice and Prediction of Thermodynamic Parameters Using ANN and ANFIS Algorithms. Energies 2021, 14, 4838. [CrossRef]

61. Abbaspour-Gilandeh, Y.; Jahanbakhshi, A.; Kaveh, M. Prediction kinetic, energy and exergy of quince under hot air dryer using ANNs and ANFIS. Food Sci. Nutr. 2020, 8, 594-611. [CrossRef] 